\title{
Apathy is associated with faster global cognitive decline and early nursing home admission in dementia with Lewy bodies
}

\author{
Monica H. Breitve ${ }^{1,2,3 *} \mathbb{D}$, Kolbjørn Brønnick ${ }^{4,5}$, Luiza J. Chwiszczuk ${ }^{1,2,3}$, Minna J. Hynninen ${ }^{6,7}$, Dag Aarsland ${ }^{8,9}$ \\ and Arvid Rongve $e^{1,2,3}$
}

\begin{abstract}
Background: Little is known about the consequences of apathy in dementia with Lewy bodies (DLB), because previous research on apathy in dementia focused mainly on Alzheimer's disease (AD).

Methods: In this longitudinal study, we included patients with $A D(n=128)$ and patients with DLB $(n=81)$. At baseline, we analyzed the associations between apathy and cognition in the total sample and in AD and DLB separately. Generalized linear mixed models were used to investigate the association between apathy and Mini Mental State Examination (MMSE) over 4 years, and the Kaplan-Meier method was used to assess the association between apathy and survival or nursing home admission.

Results: In patients with DLB, apathy was associated with a faster global cognitive decline (MMSE) over 4 years. Patients with DLB and apathy had shorter time until nursing home admission than DLB patients without apathy and patients with $A D$, regardless of apathy. At baseline, patients with apathy had decreased performance on the Stroop color test and a composite executive function score. Neurocognition was unaffected by apathy in AD, but DLB patients with apathy had more verbal learning difficulties.

Conclusions: Apathy seems to be associated with more serious symptomatology in DLB than in AD. It is important to focus on apathy in dementia because it is one of the most prevalent and disturbing behavioral and psychological symptoms.
\end{abstract}

Keywords: Dementia, Alzheimer's disease, Dementia with Lewy bodies, Apathy, Neuropsychology, Longitudinal, Survival

\section{Background}

Apathy, defined as reduced motivation, reduced voluntary and goal-directed behavior, or reduced social interests and emotional blunting [1], is one of the most prevalent and important neuropsychiatric symptoms in dementia [2-4]. Reported apathy prevalence rates for outpatients with Alzheimer's disease (AD) lie between $25 \%$ and $93 \%$, and estimates exceed $50 \%$ for patients with mild dementia with Lewy bodies (DLB) $[2,5]$. Apathy can be divided into cognitive, motor, and affective symptoms, depending on the

\footnotetext{
* Correspondence: monica.breitve@helse-fonna.no

'Department of Research and Innovation, Helse Fonna HF Haugesund Hospital, Postbox 2170, N-5504 Haugesund, Norway

${ }^{2}$ Department of Geriatric Psychiatry, Clinic of Psychiatry, Helse Fonna HF Haugesund Hospital, Postbox 2170, N-5504 Haugesund, Norway Full list of author information is available at the end of the article
}

most affected prefrontal-basal ganglia circuits. However, the neurobiology of apathy is still not well understood [4].

Symptoms seen in neuropsychiatric disorders can mask, mimic, or enhance apathy. Apathy is highly correlated with depression in patients with $\mathrm{AD}$ [6], and the two can be difficult to separate owing to overlapping symptoms. Nonetheless, apathy is a distinct syndrome from depression [7]. It is characterized by a lack of negative thoughts, less emotional distress, less sadness, less vegetative symptoms, and fewer somatic complaints than typically seen in depression [4].

Apathy in $\mathrm{AD}$ is associated with increased caregiver burden [8], decreased functioning in activities of daily living (ADL) [9], and more morbidity [10]. The presence of apathy in patients with mild cognitive impairment

(C) The Author(s). 2018 Open Access This article is distributed under the terms of the Creative Commons Attribution 4.0 International License (http://creativecommons.org/licenses/by/4.0/), which permits unrestricted use, distribution, and 
increases the risk of conversion to AD [11]. Previous findings regarding cognitive dysfunction in patients with apathy are contradictory. It has been reported that in AD, patients with apathy have lower Mini Mental State Examination (MMSE) scores than patients without apathy [12], whereas others have found no differences [13-15]. In studies that also included a small number of patients with DLB, no associations were found between apathy and MMSE scores $[16,17]$. In neuropsychological tests, patients with $\mathrm{AD}$ and apathy have demonstrated more impairment in impulse control $[18,19]$, attention [18], visual memory [15], verbal memory [13, 18], naming, phonological verbal fluency [13], and semantic verbal fluency [14] than patients with AD without apathy. For patients with DLB, there were no associations between apathy and verbal memory, phonemic verbal fluency, and naming, except for a negative correlation between apathy and an executive task of sorting [17]. Patients with AD that, during a period of 1-4 years, developed apathy showed a faster cognitive and ADL decline than patients who did not develop apathy [7]. Even though an apathy-executive function syndrome has been described in different dementias, and although apathy rather than depression influences executive skills [20], the results of previous research are internally contradictory and inconclusive.

In extreme cases, apathy can be seen as a way of dying, because adequate response to changes in the environment is necessary for survival. The association between apathy and higher mortality is well documented in patients with $\mathrm{AD}[10,21]$. Apathy may also lead to faster nursing home admission for patients with AD [22].

There are few studies regarding apathy in $\mathrm{AD}$ and particularly few in DLB. We therefore investigated whether apathy was associated with shorter survival and higher risk of nursing home admission, as well as if apathy was associated with cognitive impairment at baseline. Finally, we examined if apathy was associated with faster global cognitive decline over 4 years as measured by MMSE. All analyses were performed in the total sample and stratified in AD and DLB.

\section{Methods}

\section{Subjects}

In a longitudinal dementia study in western Norway (DemVest), 266 outpatients with a first-time diagnosis of dementia (by MMSE [23] score of at least 20 or Clinical Dementia Rating [CDR] 1 [24]) at clinics of old age psychiatry or geriatric medicine were included and followed annually from 2005 (see Fig. 1). Acute delirium, confusion, terminal illness, bipolar or psychotic disorder, or recently diagnosed major somatic illness were causes for exclusion. The current study sample comprises patients diagnosed with AD $(n=128)$ and DLB $(n=81)$. The study was approved by the Regional Committee for Medical and Health Research Ethics in Western Norway

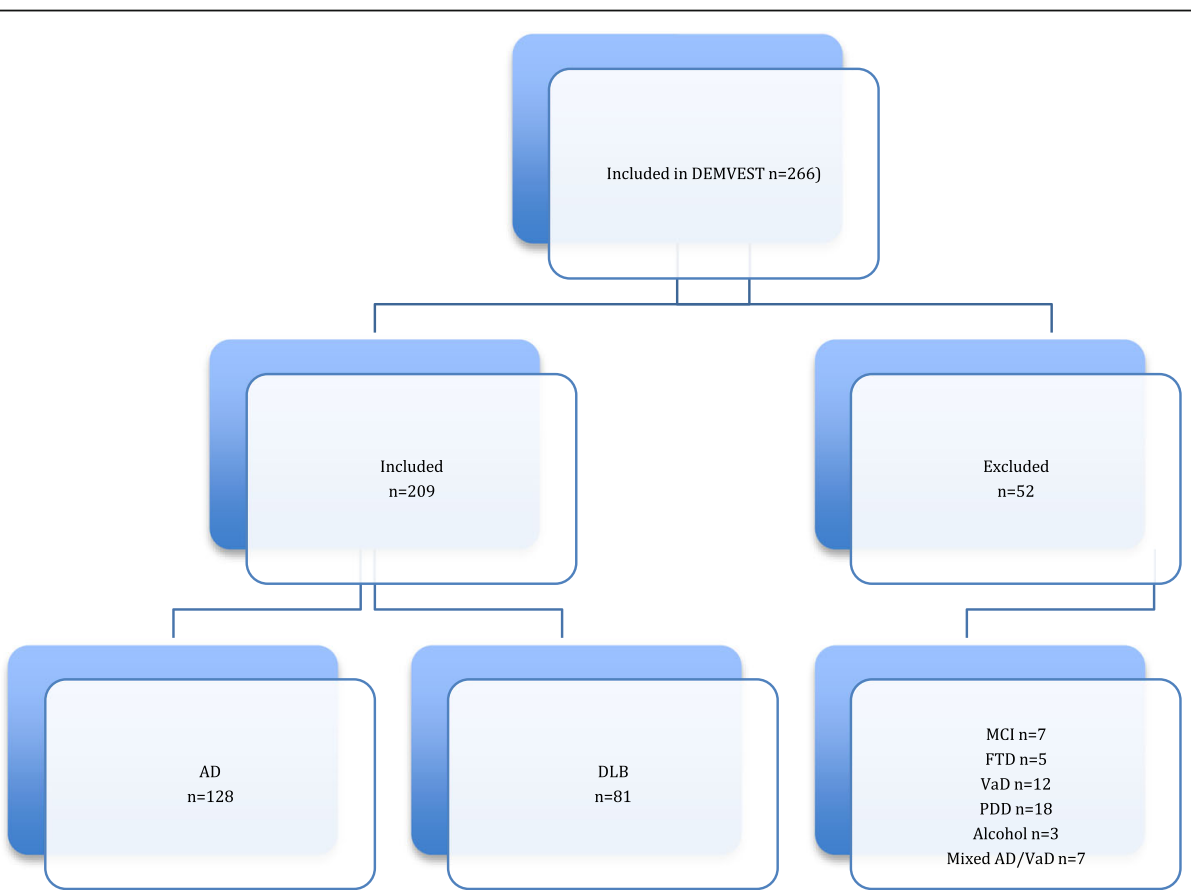

Fig. 1 Study flowchart. AD Alzheimer's disease, DLB Dementia with Lewy bodies, FTD Frontotemporal dementia, MCI Mild cognitive impairment, VaD Vascular dementia, PDD Parkinson's disease dementia, DEMVEST Dementia Study of Western Norway 
and the Norwegian Social Science Data Services. Patients gave written consent to participate.

\section{Measures \\ Dementia diagnosis}

At baseline, two independent raters set the dementia diagnoses on the basis of criteria of the Diagnostic and Statistical Manual of Mental Disorders, Fourth Edition. The diagnoses were revised by an expert team after 2 and 5 years, and the last revised diagnoses were used in the analyses. DLB diagnosis was made according to the revised consensus criteria of McKeith et al. [25], and AD diagnosis was made according to the criteria of the National Institute of Neurological and Communicative Disorders and Stroke-Alzheimer's Disease and Related Disorders Association [26]. Cerebral magnetic resonance imaging or computed tomography was conducted in all patients to exclude other causes of dementia. Ioflupane single-photon emission computed tomography $\left({ }^{123} \mathrm{I}\right.$-FP-CIT SPECT; DaTSCAN) was performed in 55 of the patients. Diagnoses were neuropathologically confirmed in a subsample.

\section{Clinical and cognitive measures}

Apathy, depression, and caregiver stress were rated by caregivers using the Neuropsychiatric Inventory (NPI) [27]. Symptoms were assessed for the last 30 days, in frequency (1-4) and severity (1-3), here applied both as a computed continuous variable (frequency $\times$ intensity) and as a dichotomized variable (clinically vs non-clinically significant), where a score above 3 was seen as clinically significant [5]. The Unified Parkinson's Disease Rating Scale [28] was used for rating parkinsonism, and the patients' general health status was measured by the Cumulative Illness Rating Scale (CIRS) [29]. The CDR [24] global score was used for measuring global dementia severity, and the MMSE [23] was used for cognitive screening. The 15-item Boston Naming Test [30] was used to measure naming. Executive functions were measured by the Stroop test [31], Controlled Oral Word Association Test (COWAT) semantic fluency [32], Trail Making Test A (TMT A) [33], and MMSE subtraction or backward spelling. Verbal learning and memory were measured with the California Verbal Learning Test, Second Edition (CVLT-II) [34], and MMSE delayed recall. Visuospatial function was measured by silhouettes and cubes on the Visual Object and Space Perception Battery [35] and MMSE pentagon. Raw scores were used, except when analyzing domains, in which case we used raw scores standardized into z-scores that were computed into neuropsychological domains. The raw scores on the TMT A were reversed for the analyses.

\section{Statistical analyses}

Statistical analyses were conducted with IBM SPSS Statistics version 23.0 software (IBM, Armonk, NY, USA).
Differences at baseline were analyzed with the $t$ test for normal distributions, the Mann-Whitney $U$ test for nonnormally distributed data, and the Pearson's chi-square test for categorical data. Univariate analysis of variance was used to control for depression. Analyses were performed on the total sample and stratified into $\mathrm{AD}$ and DLB. Survival analysis was done with the Kaplan-Meier method, and Cox regression was used to control for age at inclusion, depression, and caregiver stress. Generalized linear mixed models (GLMMs) were used for assessing the association between apathy and MMSE scores over time (apathy $\times$ time $\times$ MMSE), with the confounders sex, age, education, and depression entered as covariates. Subjects were set as random effects to correct for dependency of repeated measures, using a first-order autoregressive structure with homogeneous variance and gamma distribution with a log link.

\section{Results \\ Baseline analysis}

In the total sample, when comparing patients with apathy and those without apathy, we found a lower percentage of patients with $\mathrm{AD}$, fewer women, and fewer patients on dementia medication among patients with apathy. Patients with apathy had higher scores on the CDR global, NPI depression scale, and CIRS (see Table 1). In neuropsychological tests, patients with apathy had decreased performance on the Stroop color test and COWAT animals, as well as lower computed scores on tests measuring executive functions. After controlling for depression, the COWAT animals test was no longer significant (see Table 2). When stratifying the analyses according to dementia diagnosis, we observed that patients with $\mathrm{AD}$ and apathy had higher scores on the CDR global score, meaning more advanced dementia, and the NPI depression scale (i.e., more depressive symptoms reported by caregivers). There were no significant differences in neuropsychological tests between patients with and without apathy, and the difference in the executive domain also disappeared. Patients with DLB and apathy had higher depression scores and decreased learning on CVLT-II List A total, even after controlling for depression, than patients with DLB without apathy (see Table 2).

\section{Longitudinal analysis}

In patients with DLB, there was a statistically significant association between apathy and decline in MMSE scores over 4 years (main effect $F=2.045, p=.006$ ). There were no significant differences in the total sample or in the AD group. At baseline, apathy was not associated with survival or nursing home admission for the total sample. Patients with DLB lived shorter than patients with AD ( $p \leq .001$ ) (median 4.0/4.6 vs 7.1/7.2 years), but there 
Table 1 Characteristics of patients with and without apathy at baseline

\begin{tabular}{|c|c|c|c|c|c|c|c|c|c|}
\hline & \multicolumn{3}{|l|}{ Total sample } & \multicolumn{3}{|l|}{$A D$} & \multicolumn{3}{|l|}{ DLB } \\
\hline & $\begin{array}{l}\text { Nonapathy } \\
(n=124)\end{array}$ & $\begin{array}{l}\text { Apathy } \\
(n=72)\end{array}$ & $\begin{array}{l}p \\
\text { Value* }\end{array}$ & $\begin{array}{l}\text { Nonapathy } \\
(n=85)\end{array}$ & $\begin{array}{l}\text { Apathy } \\
(n=35)\end{array}$ & $p$ Value & $\begin{array}{l}\text { Nonapathy } \\
(n=39)\end{array}$ & $\begin{array}{l}\text { Apathy } \\
(n=37)\end{array}$ & $p$ Value $^{*}$ \\
\hline AD/DLB (\%) & $68.5 / 31.5$ & $\begin{array}{l}48.6 / \\
51.4\end{array}$ & .006 & & & & & & \\
\hline Sex, male/female & $39 / 85$ & $33 / 39$ & .044 & $64 / 21$ & $22 / 13$ & .169 & $21 / 18$ & $17 / 20$ & .491 \\
\hline Age, years (SD) & $76.2(7.2)$ & $\begin{array}{l}75.8 \\
(8.6)\end{array}$ & .702 & $75.7(7.7)$ & $\begin{array}{l}75.7 \\
(7.8)\end{array}$ & .865 & $77.3(5.9)$ & $\begin{array}{l}75.9 \\
(8.2)\end{array}$ & .382 \\
\hline Education, years (SD) & $9.8(3.1)$ & $9.3(2.6)$ & .311 & $9.7(3.1)$ & $9.2(2.3)$ & .497 & $9.9(3.0)$ & $9.4(2.9)$ & .400 \\
\hline CDR global (IQR) & $0.8(0.5)$ & $1.0(0.0)$ & $<.001$ & $0.7(0.5)$ & $1.0(0.0)$ & $<.001$ & $0.9(0.5)$ & $1.1(0.4)$ & .072 \\
\hline Depression, NPI (SD) & $1.4(1.9)$ & $3.2(3.1)$ & $<.001$ & $1.4(1.9)$ & $3.2(3.1)$ & .001 & $1.3(1.8)$ & $3.2(3.0)$ & .003 \\
\hline UPDRS (SD) & $6.4(10.6)$ & $\begin{array}{l}7.6 \\
(10.4)\end{array}$ & .175 & $1.5(2.6)$ & $2.5(4.0)$ & .296 & 15.9 (13.6) & $\begin{array}{l}12.4 \\
(12.2)\end{array}$ & .245 \\
\hline CIRS (SD) & $5.5(2.4)$ & $6.3(2.7)$ & .034 & $5.1(2.1)$ & $5.7(2.5)$ & .244 & $6.5(2.9)$ & $6.8(2.8)$ & .641 \\
\hline $\begin{array}{l}\text { Duration of dementia symptoms before baseline, } \\
\text { months (SD) }\end{array}$ & $34.8(21.9)$ & $\begin{array}{l}40.8 \\
(24.7)\end{array}$ & .104 & $32.4(21.3)$ & $\begin{array}{l}36.6 \\
(22.5)\end{array}$ & .298 & $40.0(22.4)$ & $\begin{array}{l}44.9 \\
(26.4)\end{array}$ & .396 \\
\hline Dementia medication at baseline, yes (\%) & 52.7 & 35.8 & .029 & 51.9 & 41.2 & .296 & 54.8 & 30.3 & .047 \\
\hline Dementia medication at follow-up 1, yes (\%) & 74.5 & 79.6 & .477 & 71.6 & 80.0 & .384 & 81.5 & 79.2 & .835 \\
\hline
\end{tabular}

Abbreviations: AD Alzheimer's disease, DLB Dementia with Lewy bodies, CDR Clinical Dementia Rating, CIRS Cumulative Illness Rating Scale, UPDRS Unified Parkinson's Disease Rating Scale

* Differences were analyzed using the Mann-Whitney $U$ test and Pearson's chi-square test

Table 2 Neuropsychological test scores at baseline in patients with and without apathy

\begin{tabular}{|c|c|c|c|c|c|c|c|c|c|}
\hline & \multicolumn{3}{|l|}{ Total sample } & \multicolumn{3}{|l|}{$A D$} & \multicolumn{3}{|l|}{ DLB } \\
\hline & $\begin{array}{l}\text { Nonapathy } \\
(n=124)\end{array}$ & $\begin{array}{l}\text { Apathy } \\
(n=72)\end{array}$ & $p$ Value* & $\begin{array}{l}\text { Nonapathy } \\
(n=85)\end{array}$ & $\begin{array}{l}\text { Apathy } \\
(n=35)\end{array}$ & $p$ value* & $\begin{array}{l}\text { Nonapathy } \\
(n=39)\end{array}$ & $\begin{array}{l}\text { Apathy } \\
(n=37)\end{array}$ & $p$ Value $^{*}$ \\
\hline MMSE total (SD) & $23.6(2.6)$ & $23.4(2.8)$ & .415 & $23.7(2.5)$ & $23.6(2.2)$ & .486 & $23.4(3.0)$ & $23.11(3.3)$ & .736 \\
\hline MMSE pentagon, correct copy (\%) & 61.8 & 51.4 & .102 & 70.9 & 61.8 & .340 & 48.4 & 45.5 & .814 \\
\hline MMSE subtraction/word (SD) & $3.7(1.4)$ & $3.6(1.6)$ & .973 & $4.0(1.3)$ & $4.0(1.4)$ & .593 & $3.2(1.5)$ & $3.3(1.8)$ & .862 \\
\hline MMSE memory (SD) & $1.0(1.0)$ & $1.0(1.0)$ & .886 & $0.8(0.9)$ & $0.6(0.8)$ & .462 & $1.4(0.9)$ & $1.4(1.1)$ & .870 \\
\hline CVLT-II List A total (SD) & $20.4(7.5)$ & $18.8(9.2)$ & .092 & $18.5(6.4)$ & $18.6(7.7)$ & .695 & $24.5(8.3)$ & $19.1(10.5)$ & .020 \\
\hline CVLT-II delayed recall (SD) & $1.9(2.4)$ & $1.6(2.2)$ & .416 & $1.4(1.9)$ & $1.2(2.1)$ & .496 & $3.1(2.8)$ & $2.1(2.3)$ & .141 \\
\hline VOSP silhouettes (SD) & $13.7(5.0)$ & $12.9(5.2)$ & .269 & $13.8(5.2)$ & $13.0(6.2)$ & .480 & $13.7(4.6)$ & $12.8(4.2)$ & .084 \\
\hline VOSP cubes (SD) & $6.4(3.1)$ & $6.5(3.0)$ & .885 & $7.2(2.3)$ & $7.4(2.3)$ & .711 & $5.2(3.7)$ & $5.6(3.5)$ & .652 \\
\hline BNT (SD) & $10.1(2.9)$ & $10.8(2.9)$ & .165 & $10.1(3.1)$ & $10.4(3.2)$ & .644 & $10.1(2.4)$ & $11.1(2.5)$ & .146 \\
\hline Stroop word (SD) & $69.4(22.9)$ & $62.6(20.6)$ & .087 & $75.9(22.2)$ & $70.3(18.3)$ & .260 & $55.1(17.4)$ & $54.4(20.1)$ & .111 \\
\hline Stroop color (SD) & $44.0(15.6)$ & $38.5(14.5)$ & .021 & $47.4(15.6)$ & $43.0(11.6)$ & .148 & $36.3(12.5)$ & $33.7(15.9)$ & .302 \\
\hline Stroop color-word (SD) & $16.2(0.9)$ & $13.4(8.3)$ & .133 & $18.3(11.5)$ & $13.9(8.9)$ & .103 & $11.5(7.3)$ & $13.0(7.7)$ & .405 \\
\hline COWAT animals (SD) & $12.2(4.4)$ & $10.7(4.4)$ & .014 & $12.3(4.2)$ & $11.2(4.4)$ & .146 & $12.0(4.7)$ & $10.3(4.4)$ & .108 \\
\hline Trail Making Test A (SD) & $111.0(69.0)$ & $124.2(92.1)$ & .686 & $96.8(63.7)$ & $113.4(82.1)$ & .544 & $143.1(70.3)$ & $136.1(101.9)$ & .173 \\
\hline Memory domain, z-scores (SD) & $0.03(0.8)$ & $-0.04(0.9)$ & .395 & $-0.17(0.87)$ & $-0.25(0.8)$ & .422 & $0.48(0.8)$ & $0.15(0.9)$ & .152 \\
\hline Visuospatial domain, z-scores (SD) & $0.06(0.7)$ & $-0.09(0.7)$ & .132 & $0.17(0.7)$ & $0.06(0.8)$ & .406 & $-0.17(0.8)$ & $-0.22(0.69)$ & .652 \\
\hline Executive domain, z-scores (SD) & $0.08(0.7)$ & $-0.18(0.8)$ & .014 & $0.30(0.6)$ & $0.05(0.6)$ & .104 & $-0.30(0.6)$ & $-0.39(0.8)$ & .823 \\
\hline
\end{tabular}

Abbreviations: AD Alzheimer's disease, BNT Boston Naming Test, COWAT Controlled Oral Word Association Test, CVLT-II California Verbal Learning Test, Second Edition, DLB Dementia with Lewy bodies, MMSE Mini Mental State Examination, VOSP Visual Object and Space Perception Battery

*Differences were analyzed using the Mann-Whitney $U$ test and Pearson's chi-square test 
was no significant difference between patients with or without clinically significant apathy. Patients with DLB and clinically significant apathy had a shorter time until nursing home admission than patients with DLB and no apathy, or than patients with $\mathrm{AD}$, regardless of apathy ( $p=.001)$ (median 2.0 vs $3.2 / 3.5 / 3.7$ years) (see Fig. 2).

\section{Discussion}

Patients with dementia and apathy had reduced executive function as measured in neuropsychological domains and in the Stroop color test, even after controlling for depression, which was moderately correlated with apathy. When comparing AD and DLB separately, the only significant difference was found in the DLB group, where patients with apathy had more verbal learning deficits than the nonapathy group. This could be explained by patients with AD having temporal lobe deficits and difficulties with learning in general, regardless of frontal lobe function/apathy. In DLB where temporal lobe pathology is not advanced, patients with apathy and frontal lobe dysfunction/apathy have deficits in using learning strategies that are controlled by the frontal lobes and have scores at the same level as patients with AD. However, we found no significant differences in the executive domain in the DLB group, which then would have been expected. In the executive domain, we included a test typically associated with attention. The relationship between attention and executive functions is still debated. It has been suggested that they are interrelated but have different anatomical components [36], so the use of a too-wide concept for the executive domain and too few or suboptimal executive tests (i.e., semantic fluency instead of phonological fluency) could explain the internal contradictory result. There was also more use of dementia medication in the nonapathy DLB group, which could have a positive effect on apathy and cognition. In addition, multiple analyses were performed, so there is a risk of committing family-wise statistical errors (inflated risk of type I errors). It should also be noted, as previously mentioned, that other studies have found worse cognitive performance in $\mathrm{AD}$ patients with apathy than in patients without apathy $[13-15,18,19]$.

In sum, the results are not as expected, because in general we found few significant associations with apathy for neuropsychological tests at baseline. On the basis of previous studies, including studies by our group, there is a lack of strong support for the apathy-dysexecutive-frontal syndrome in cognitive tests, whereas it is clearly supported in brain function studies with different approaches [37]. There are only a few studies regarding apathy and neuropsychological tests, and the numbers of patients are often small; therefore, unexpected nonsignificant results could be due to low statistical power. To the best of our knowledge of this literature, we have included the largest number of patients with DLB and the third largest number of patients with $\mathrm{AD}$.

In patients with DLB, we found that apathy was associated with a faster progression in MMSE over 4 years, and it was not explained by depression. Neither is it likely to be caused by the use of dementia medication, because the same number of patients used these drugs after the day of inclusion. The observation may be a

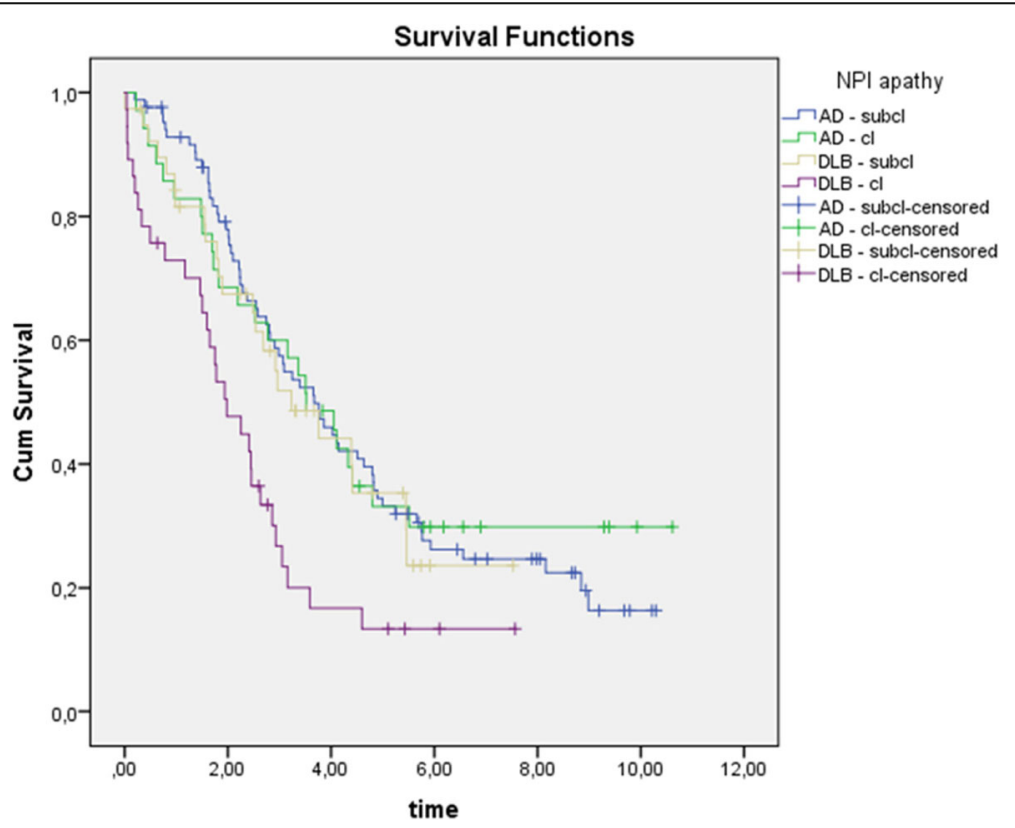

Fig. 2 Time until nursing home admission. AD Alzheimer's disease, DLB Dementia with Lewy bodies 
result of more negative interactions between apathy and other Behavioral and Psychological Symptoms of Dementia (BPSD), such as visual hallucinations, that are more prevalent in DLB than in AD, which also are correlated with executive dysfunction [38]. It could also be due to differences in genetic profiles and cortical pathology. If dementia medication had a hypothetical positive effect on apathy and progression, this effect would have had its origin from before the patients were included in the study.

Patients with DLB had shorter survival time than patients with $\mathrm{AD}$, but this was not associated with apathy. Several previous studies have also indicated a shorter survival in DLB than in $\mathrm{AD}[39,40]$. On one hand, time until nursing home admission was more than 1 year shorter for DLB with apathy than for those without, but on the other hand, we found the same rate of survival for the two groups. If we put forward the premise that patients, at group levels, are expected to live approximately the same period of time after nursing home admission, we could hypothetically explain the equal time of survival by better caregiving, more activity, and treatment at the nursing home. This counteracts apathy and helps patients with DLB and apathy live as long as patients with DLB without apathy. There were no statistical differences in health status for patients with and without apathy in DLB, and therefore this could not explain the observation. We do not have information about the quality of caregiver support, but caregiver stress did not influence the results.

Some caution should be taken when interpreting the results. There were some missing data, because a natural consequence of studying patients who are elderly and have a progressing disease. GLMM analyses are an appropriate approach that can compensate to some degree for missing data at random.

As anyone who has performed neuropsychological testing of apathetic patients knows, these patients' lack of motivation to perform on tests is an obvious problem. We do not have information about the patients' test effort and therefore could not control for it in the analyses. We have not discussed different types of apathy or the concept of apathy and differential symptoms/diagnosis, but we have operationalized it as what is measured by the apathy subscale on the NPI, rated by the caregivers. Neither did we include information from the patients, because apathy and insight are negatively correlated and will affect validity [4]. Some have asked for a unified assessment tool for apathy in the dementia population. The NPI is one of the most often used instruments for assessing BPSD in patients with dementia and should adequately assess apathy and depression independently [41], but it should be noted that only few studies have investigated the psychometric properties of the NPI in the DLB population.
The MMSE, which was used in the longitudinal analyses, is also often criticized for not having high sensitivity for changes in cognition in pure DLB [42]. However, the test has been found to be valid in patients with Parkinson's disease, who share similar pathology to patients with DLB [43].

In this study, we performed multiple analyses at baseline, and there is a legitimate possibility of observing significant results simply due to chance. However, by using methods such as the Bonferroni correction, we could risk rejecting $\mathrm{H} 1$ even if it were true (type II error). Because we mainly had negative results, and because the consequence of falsely stating that apathy has no negative associations could be worse than the opposite, we chose not to adjust the alpha-level. Nevertheless, we acknowledge that an analytic approach defined purely a priori would have yielded more robust results.

A strength of the study is that it provides knowledge about apathy in DLB, which is an issue that has not been addressed before and can offer useful information to patients, their caregivers, clinicians, and the community. It provides information on prognosis and focuses on apathy in dementia, which should be assessed and intervened when necessary. The study also has a relatively large number of patients with DLB, and they were followed over 4 years with regard to cognition, and longer for nursing home admission and survival. Patients were thoroughly evaluated and diagnosed (i.e., the majority of patients with DLB had undergone ${ }^{123}$ I-FP-CIT SPECT [DaTSCAN]), including brain autopsy. We have previously reported that in our sample, autopsy in 43 cases showed $92 \%$ sensitivity and $83 \%$ specificity for the clinical diagnoses [44].

\section{Conclusions}

Apathy seems to be associated with more serious consequences in DLB than in AD. Although there were only few differences in neuropsychological tests at baseline, apathy in patients with DLB was associated with faster cognitive decline in MMSE over 4 years and shorter time until nursing home admission. It is important to focus on apathy in dementia because it is one of the most prevalent BPSD symptoms, and interventions are required when apathy is present. More research is needed (i.e., studies with more patients with DLB) that differentiates apathy into subcategories and includes genetic information and pathologically confirmed diagnosis.

\footnotetext{
Abbreviations

${ }^{123}$ I-FP-CIT SPECT: loflupane single-photon emission computed tomography; AD: Alzheimer's disease; ADL: Activities of daily living; BNT: Boston Naming Test; BPSD: Behavioral and Psychological Symptoms of Dementia; CDR: Clinical Dementia Rating; CIRS: Cumulative Illness Rating Scale; COWAT: Controlled Oral Word Association Test; CVLT-II: California Verbal Learning Test, Second Edition; DEMVEST: Dementia Study of Western Norway; DLB: Dementia with Lewy bodies; FTD: Frontotemporal dementia;
} 
MCl: Mild cognitive impairment; MMSE: Mini Mental State Examination; NPI: Neuropsychiatric Inventory; PDD: Parkinson's disease dementia; TMT A: Trail Making Test A; UPDRS: Unified Parkinson's Disease Rating Scale; VaD: Vascular dementia; VOSP: Visual Object and Space Perception Battery

\section{Acknowledgements}

First and foremost, we thank the patients and their caregivers who participated in the study. We also thank Mien Parlati for plotting data and Jörg Assmus and Thomas Eilertsen for consultation in data analysis. DA thanks the Wolfson Foundation and the Royal Society for their support.

\section{Funding}

The DemVest study is funded by the Western Norway Regional Health Authority.

\section{Availability of data and materials}

The reported data are owned by the DemVest study, and, owing to ethical issues, they cannot be made publicly accessible, but the data set can be made available for the reviewers on request.

\section{Authors' contributions}

MHB participated in data acquisition, conceived of the hypothesis, analyzed and interpreted data, and drafted the manuscript. KB and LJC contributed to the hypothesis, analyzed and interpreted data, and revised the manuscript. $\mathrm{MJH}$ interpreted the analysis and revised the manuscript. DA participated in data acquisition and interpretation of the analysis and revised the manuscript. AR participated in data acquisition, contributed to the hypothesis and interpretation of the analysis, and revised the manuscript. All authors read and approved the final version of the manuscript.

\section{Ethics approval and consent to participate}

The study was approved by the Regional Committee for Medical and Health Research Ethics in Western Norway (REK) and the Norwegian Social Science Data Services (REK number 167.04). Patients gave written consent to participate.

\section{Competing interests}

DA has received research support and/or honoraria from AstraZeneca, $\mathrm{H}$. Lundbeck, Novartis Pharmaceuticals, and GE Health and has served as a paid consultant for H. Lundbeck, Eisai, and Evonik. DA is also a Royal Society Wolfson Research Merit Award holder. This study represents independent research partly funded by the National Institute for Health Research (NIHR) Biomedical Research Unit for Dementia at South London and Maudsley NHS Foundation Trust and King's College London. The views expressed are those of the authors and not necessarily those of the NHS, the NIHR, or the Department of Health.

\section{Publisher's Note}

Springer Nature remains neutral with regard to jurisdictional claims in published maps and institutional affiliations.

\section{Author details}

'Department of Research and Innovation, Helse Fonna HF Haugesund Hospital, Postbox 2170, N-5504 Haugesund, Norway. ${ }^{2}$ Department of Geriatric Psychiatry, Clinic of Psychiatry, Helse Fonna HF Haugesund Hospital, Postbox 2170, N-5504 Haugesund, Norway. ${ }^{3}$ Faculty of Medicine, University of Bergen, Postbox 7804, 5020 Bergen, Norway. ${ }^{4}$ TIPS - Centre for Clinical Research in Psychosis, Stavanger University Hospital, 4011 Stavanger, Norway. ${ }^{5}$ Network for Medical Sciences, University of Stavanger, 4036 Stavanger, Norway. ${ }^{6}$ Department of Clinical Psychology, University of Bergen, Christies gate 12, 5015 Bergen, Norway. ${ }^{7}$ NKS Olaviken Gerontopsychiatric Hospital, Askvegen 150, 5306 Erdal, Norway. ${ }^{8}$ Center for Age-Related Diseases (SESAM), Stavanger University Hospital, Armauer Hansens vei 20, 4011 Stavanger, Norway. ${ }^{9}$ Department of Old Age Psychiatry, Institute of Psychiatry and Neuroscience, King's College, London, UK.
Received: 18 April 2018 Accepted: 31 July 2018

Published online: 18 August 2018

\section{References}

1. Robert P, Onyike CU, Leentjens AF, Dujardin K, Aalten P, Starkstein S, et al. Proposed diagnostic criteria for apathy in Alzheimer's disease and other neuropsychiatric disorders. Eur Psychiatry. 2009;24(2):98-104. https://doi.org/ 10.1016/j.eurpsy.2008.09.001.

2. Bjoerke-Bertheussen J, Ehrt U, Rongve A, Ballard C, Aarsland D. Neuropsychiatric symptoms in mild dementia with Lewy bodies and Alzheimer's disease. Dement Geriatr Cogn Disord. 2012;34(1):1-6. https://doi. org/10.1159/000339590.

3. van der Linde RM, Stephan BC, Savva GM, Dening T, Brayne C. Systematic reviews on behavioural and psychological symptoms in the older or demented population. Alzheimers Res Ther. 2012;4:28. https://doi.org/10. 1186/alzrt131.

4. Cipriani G, Lucetti C, Danti S, Nuti A. Apathy and dementia. nosology, assessment and management. J Nerv Ment Dis. 2014;202(10):718-24. https://doi.org/10.1097/NMD.0000000000000190.

5. Chau SA, Chung J, Herrmann N, Eizenman M, Lanctôt KL. Apathy and attentional biases in Alzheimer's disease. J Alzheimers Dis. 2016;51(3):83746. https://doi.org/10.3233/JAD-151026.

6. Levy ML, Miller BL, Cummings JL, Fairbanks LA, Craig A. Alzheimer disease and frontotemporal dementias. behavioral distinctions. Arch Neurol. 1996; 53(7):687-90.

7. Starkstein SE, Jorge R, Mizrahi R, Robinson RG. A prospective longitudinal study of apathy in Alzheimer's disease. J Neurol Neurosurg Psychiatry. 2006; 77(1):8-11.

8. Landes AM, Sperry SD, Strauss ME, Geldmacher DS. Apathy in Alzheimer's disease. J Am Geriatr Soc. 2001;49(12):1700-7.

9. You SC, Walsh CM, Chiodo LA, Ketelle R, Miller BL, Kramer JH. Neuropsychiatric symptoms predict functional status in Alzheimer's disease. J Alzheimers Dis. 2015;48(3):863-9. https://doi.org/10.3233/JAD-150018.

10. van der Linde RM, Dening T, Stephan BC, Prina AM, Evans E, Brayne C. Longitudinal course of behavioural and psychological symptoms of dementia: systematic review. Br J Psychiatry. 2016;209(5):366-77.

11. Robert PH, Berr C, Volteau M, Bertogliati C, Benoit M, Mahieux F, et al. Neuropsychological performance in mild cognitive impairment with and without apathy. Dement Geriatr Cogn Disord. 2006;21(3):192-7. https://doi. org/10.1159/000090766.

12. Starkstein SE, Ingram L, Garau ML, Mizrahi R. On the overlap between apathy and depression in dementia. J Neurol Neurosurg Psychiatry. 2005; 76(8):1070-4.

13. Kuzis G, Sabe L, Tiberti C, Dorrego F, Starkstein SE, Neuropsychological correlates of apathy and depression in patients with dementia. Neurology. 1999;52(7):1403-7.

14. Drijgers RL, Verhey FR, Leentjens AF, Köhler S, Aalten P. Neuropsychological correlates of apathy in mild cognitive impairment and Alzheimer's disease: the role of executive functioning. Int Psychogeriatr. 2011;23(8):1327-33. https://doi.org/10.1017/S1041610211001037.

15. Guimaraes HC, Fialho PP, Carvalho VA, Machado TH, Santos EL, Caramelli P. Apathy is not associated with performance in brief executive tests in patients with mild cognitive impairment and mild Alzheimer's disease. Curr Alzheimer Res. 2014;11(8):792-8. https://doi.org/10.2174/ 156720501108140910122509.

16. Clarke DE, van Reekum R, Simard M, Streiner DL, Conn D, Cohen T, et al. Apathy in dementia: clinical and sociodemographic correlates. J Neuropsychiatry Clin Neurosci. 2008;20(3):337-47. https://doi.org/10.1176/ appi.neuropsych.20.3.337.

17. Perri R, Monaco M, Fadda L, Caltagirone C, Carlesimo GA. Neuropsychological correlates of behavioral symptoms in Alzheimer's disease, frontal variant of frontotemporal, subcortical vascular, and Lewy body dementias: a comparative study. J Alzheimers Dis. 2014;39(3):669-77. https://doi.org/10.3233/JAD-131337.

18. McPherson S, Fairbanks L, Tiken S, Cummings JL, Back-Madruga C. Apathy and executive function in Alzheimer's disease. J Int Neuropsychol Soc. 2002; 8(3):373-81

19. Grossi D, Santangelo G, Barbarulo AM, Vitale C, Castaldo G, Proto MG, et al. Apathy and related executive syndromes in dementia associated with Parkinson's disease and in Alzheimer's disease. Behav Neurol. 2013;27(4): 515-22. https://doi.org/10.3233/BEN-129023. 
20. Levy ML, Cummings JL, Fairbanks LA, Masterman D, Miller BL, Craig AH, et al. Apathy is not depression. J Neuropsychiatry Clin Neurosci. 1998;10(3) 314-9. https://doi.org/10.1176/jnp.10.3.314.

21. Spalletta G, Long JD, Robinson RG, Trequattrini A, Pizzoli S, Caltagirone C. Longitudinal neuropsychiatric predictors of death in Alzheimer's disease. J Alzheimers Dis. 2015:48(3):627-36. https://doi.org/10.3233/JAD-150391.

22. Bakker C, de Vugt ME, van Vliet D, Verhey FRJ, Pijnenburg YA, VernooijDassen MJFJ, et al. Predictors of the time to institutionalization in youngversus late-onset dementia: results from the Needs in Young Onset Dementia (NeedYD) study. J Am Med Dir Assoc. 2013;14:248-53.

23. Folstein MF, Folstein SE, McHugh PR. "Mini-mental state": a practical method for grading the cognitive state of patients for the clinician. J Psychiatr Res. 1975:12:189-98.

24. Morris JC. Clinical Dementia Rating: a reliable and valid diagnostic and staging measure for dementia of the Alzheimer type. Int Psychogeriatr. 1997;9(Suppl 1):173-6. discussion 177-8

25. McKeith IG, Dickson DW, Lowe J, Emre M, O'Brien JT, Feldman H, et al. Diagnosis and management of dementia with Lewy bodies: third report of the DLB Consortium. Neurology. 2005;65(12):1863-72.

26. McKhann G, Drachman D, Folstein M, Katzman R, Price D, Stadlan EM. Clinical diagnosis of Alzheimer's disease: report of the NINCDS-ADRDA Work Group under the auspices of Department of Health and Human Services Task Force on Alzheimer's disease. Neurology. 1984;34(7):939-44.

27. Cummings JL, Mega M, Gray K, Rosenberg-Thompson S, Carusi DA, Gornbein J. The Neuropsychiatric Inventory: comprehensive assessment of psychopathology in dementia. Neurology. 1994;44:2308-14.

28. Goetz CG, Fahn S, Martinez-Martin P, Poewe W, Sampaio C, Stebbins GT, et al. Movement Disorder Society-sponsored revision of the Unified Parkinson's Disease Rating Scale (MDS-UPDRS): process, format, and clinimetric testing plan. Mov Disord. 2007;22(1):41-7.

29. Miller MD, Paradis CF, Houck PR, Mazumdar S, Stack JA, Rifai AH, et al. Rating chronic medical illness burden in geropsychiatric practice and research: application of the Cumulative IIIness Rating Scale. Psychiatry Res. 1992;41(3):237-48.

30. Mack WJ, Freed DM, Williams BW, Henderson WW. Boston Naming Test: shortened versions for use in Alzheimer's disease. J Gerontol. 1992;47(3): 154-8.

31. Golden CJ. Stroop Colour and Word Test. Chicago: Stoelting; 1978.

32. Benton AL, Hamsher K. Multilingual aphasia examination. lowa City: University of lowa; 1976

33. Armitage SG. An analysis of certain psychological tests used for the evaluation of brain injury. Psychol Monogr. 1946;60(1):1-48. https://doi.org/ 10.1037/h0093567.

34. Delis DC, Kramer JH, Kaplan E, Ober BA. California Verbal Learning Test: adult version; manual. 2nd ed. San Antonio, TX: Psychological Corporation; 2000.

35. Warrington EK, James M. The Visual Object and Space Perception Battery. Bury St. Edmunds, UK: Thames Valley; 1991.

36. Posner Ml, Petersen SE. The attention system of the human brain. Annu Rev Neurosci. 1990;13:25-42.

37. Theleritis C, Politis A, Siarkos K, Lyketsos CG. A review of neuroimaging findings of apathy in Alzheimer's disease. Int Psychogeriatr. 2014;26(2):195-207. https://doi.org/10.1017/S1041610213001725.

38. Cagnin A, Gnoato F, Jelcic N, Favaretto S, Zarantonello G, Ermani M, et al. Clinical and cognitive correlates of visual hallucinations in dementia with Lewy bodies. J Neurol Neurosurg Psychiatry. 2013;84(5):505-10. https://doi. org/10.1136/jnnn-2012-304095.

39. Oesterhus R, Soennesyn H, Rongve A, Ballard CG, Aarsland D, Vossius C. Long-term mortality in a cohort of home-dwelling elderly with mild Alzheimer's disease and Lewy body dementia. Dement Geriatr Cogn Disord. 2014;38(3-4):161-9. https://doi.org/10.1159/000358051.

40. Price A, Faroog R, Yuan JM, Menon BV, Cardinal RN, O'Brien JT. Mortality in dementia with Lewy bodies compared with Alzheimer's dementia: a retrospective naturalistic cohort study. BMJ Open. 2017;7:e017504. https:// doi.org/10.1136/ bmjopen-2017-017504

41. Lai CK. The merits and problems of Neuropsychiatric Inventory as an assessment tool in people with dementia and other neurological disorders. Clin Interv Aging. 2014;9:1051-61.

42. Nelson PT, Kryscio RJ, Jicha GA, Abner EL, Schmitt FA, Xu LO, et al. Relative preservation of MMSE scores in autopsy-proven dementia with Lewy bodies. Neurology. 2009;73:1127-33.
43. Lessig S, Nie D, Xu R, Corey-Bloom J. Changes on brief cognitive instruments over time in Parkinson's disease. Mov Disord. 2012;27:1125-8.

44. Skogseth R, Hortobágyi T, Soennesyn H, Chwiszczuk L, Ffytche D, Rongve A, et al. Accuracy of clinical diagnosis of dementia with Lewy bodies versus neuropathology. J Alzheimers Dis. 2017;59(4):1139-52. https://doi.org/10. 3233/JAD-170274.
Ready to submit your research? Choose BMC and benefit from:

- fast, convenient online submission

- thorough peer review by experienced researchers in your field

- rapid publication on acceptance

- support for research data, including large and complex data types

- gold Open Access which fosters wider collaboration and increased citations

- maximum visibility for your research: over $100 \mathrm{M}$ website views per year

At BMC, research is always in progress.

Learn more biomedcentral.com/submissions 